\title{
The Condition of the Oral Cavity in Patients Who Have Had a Viral Infection COVID-19
}

\author{
Avzal Nigmatullaevich Akbarov \\ Head of the Department of Faculty Orthopedic Dentistry, Tashkent State Dental Institute, Uzbekistan \\ Corresponding author email: bp.corrector@gmail.com \\ Davron Nigman Ugli Xabilov \\ Assistant of the Department of Faculty Orthopedic Dentistry, Tashkent State Dental Institute, Uzbekistan
}

\begin{abstract}
Coronavirus COVID-19 is the cause of severe respiratory pathology and is a dangerous disease, proceeding in various clinical forms with varying degrees severity. This scientific paper presents a literature review of the latest collected data on the course of the novel coronavirus infection COVID-19 and its manifestations in the oral cavity during illness and after convalescence. The transmission routes of the disease and the main symptoms are also described. All healthcare systems in the world have been tasked with prompt diagnosis of coronavirus infection, specialized medical care and rehabilitation. In COVID 19 (SARS-CoV-2), changes in OOM are not the primary cause, but are manifested as a result of drug treatment and disease progression, despite the fact that the oral cavity is one of the sources of entry gate for infection.
\end{abstract}

Keywords---coronavirus, COVID-19, infection, oral cavity, prevention of complications, rehabilitation

\section{Introduction}

As of 03.08.2021 worldwide, there were 199622425 cases of confirmed incidence worldwide (including 131978 in Uzbekistan), 4250338 deaths (including 886 in Uzbekistan). COVID-19 can occur in 2 forms - severe and mild. A common complication is pneumonia, which requires oxygen therapy. The infectious disease COVID-19 is caused by the SARS-CoV-2 virus, which belongs to the large family of coronaviruses. The virus consists of single-stranded RNA, envelope and lipid layer (Saif, 1993; Qing \& Gallagher, 2020). The novel SARS-CoV-2 coronavirus, Severe Acute Respiratory Syndrome Coronavirus (SARS-CoV) and Middle East Respiratory Syndrome Coronavirus (MERS-CoV) have similar genomic sequences and belong to the same genus of beta-coraviruses (Brandini et al., 2021). Ways of transmission of COVID-19 from person to person: airborne - when sneezing or coughing, contact directly from an infected person, through infected surfaces. Transmission of infection is possible from the first day of the incubation period. The entrance gates for the virus to enter the body are the mucous membranes of the nose, mouth and eyes (Xu et al., 2020).

The target cells for infection are type II pulmonary capillary endothelial cells, esophageal epithelial cells, absorptive enterocytes of the ileum and colon, cholangiocytes, myocardial cells, cells of the proximal renal tubules and urothelial cells of the urinary bladder, namely the receptor in them - angiotensin converting enzyme (ACE2), with which the viral spine receptor binds, after which a large number of viral particles are released, the cells undergo apoptosis and die. Thus, the viral load on the body increases (Martin Karreras-Presas et al., 2020). Also, a number of studies have revealed that the ACE2 enzyme is also expressed in the oral mucosa, namely in the epithelium of the tongue. These results explained the underlying mechanism by which the oral cavity poses a potentially high risk of infection susceptibility to 2019-nCoV (Amorim dos Santos et al., 2021). 


\section{Materials, Research Methods and Discussion}

In terms of clinical symptoms, COVID-19 can present with a range of symptoms, from mild flu-like symptoms of fever, dry cough, fatigue, muscle pain and diarrhea to more serious manifestations characterized by severe pneumonia progressing to respiratory distress syndrome (ARDS). Excessive activation of systemic immunity after infection with SARS-CoV-2 causes the so-called "cytokine storm", in which the released cytokines - tumor necrosis factors (TNF), interleukin-6 (IL-6) and interleukin-1 $($ IL-1 $\beta$ ) - damage the cells of the body. This can lead to increased vascular permeability and subsequent damage to organs such as the kidneys and heart, leading to multiple organ failure and death (Kim \& Su, 2020; Tetro, 2020). The high probability of collision of the oral mucosa with viral particles is one of the first and the high content of the ACE2 2019-nCoV receptor in the epithelial cells of the tongue and salivary glands create conditions for a rapid increase in viral load and thereby increase the risk of adverse manifestations of COVID-19 disease in the oral cavity (Liang, 2020; Langford et al., 2020).

In 2021, doctors noted new consequences of the COVID-19 disease, in sick and recovering patients, inflammation, painful rash and mouth ulcers appear. Those patients who have dental diseases or diseases, the treatment of which has been delayed for a long time, for example, caries, are susceptible to oral problems. One of the main and early clinical symptoms of COVID-19 affecting the oral cavity is xerostomia and loss of gustatory sensitivity (Brandini). Independent studies were conducted by the authors Yegbali Zarh R., Hosseinzade P., they reviewed seventeen studies, including more than 170 cases with manifestations in the oral cavity in patients with COVID-19, and summarized the available data. The authors described symptoms such as dry mouth $(\mathrm{n}=75)$, acute dysgeusia (taste disturbance) $(\mathrm{n}=71)$, soreness and burning sensation of the mucous membrane of the lower lip, changes in the sensitivity of the tongue $(n=48)$, muscle pain during chewing $(n=15)$, ulceration $(n=28)$. A couple of days after the manifestation of general systemic disorders associated with the disease COVID-19, the appearance of bubbles on the oral mucosa was noted. Herpetic infection was recorded in the anamnesis. Oral manifestations regressed after a week, and systemic symptoms on day 14. The median time to onset of oral manifestation was 7.21 days after systemic symptoms (range: 10-42 days). In 42 cases, oral lesions resolved spontaneously or with basic treatment within three weeks (Xu et al., 2020).

The majority of patients (97\%), first of all, noted bad breath, while men were less likely to report halitosis relative to females. $25 \%$ of patients reported a decrease in their sense of smell after recovery. Almost every second patient $(48 \%)$ who applied for dental care noted the appearance of ulcers on the cheeks. At the same time, the patients complained of pain when eating, talking, chewing and swallowing. Against the background of the above unpleasant sensations, patients noted a loss in body weight, a decrease in appetite, some generally refused to eat because of the sensation of the taste of food "like cotton wool" and severe pain. In $61 \%$ of patients, after bacteriological examination, candidiasis was diagnosed. After the appointment of antifungal drugs, the complaints ceased (Sohrabi et al., 2020). Petechial changes occurred in $16.3 \%$ of patients. Localization of enanthemas was noted only on the hard palate. The patients' erythematous rash varied in appearance. In the latter case, millimeter petechiae without erythema on the background of non-inflamed mucous membrane were noted on the hard palate. Also, this patient noted the appearance of petechiae before the height of the COVID-19 disease, which excludes the reaction of the mucous membrane to drugs, viral etiology is probably the root cause of the development of pathology. One of the most common oral diseases in patients who have had a coronavirus infection is chronic recurrent aphthous stomatitis (Drummond et al., 1978; Su et al., 2006).

Also, patients noted dryness in the mouth, lips cracked, flaky, and may be atrophic. Patients complained of adhesion of the lips to the teeth, sometimes there were epithelial particles adhering to the vestibular surfaces of the anterior group of teeth. Patients complained of dry mouth, difficulty in chewing and swallowing. The patients were forced to drink water while eating. In a report by Brandao et al. provides information on 8 patients with active COVID-19. These patients were also found to have lesions of the oral cavity in the form of ulcers, similar to aphthous ulcers, and some also showed processes of necrosis and hemorrhagic ulcers. The time to the onset of the disease ranged from two to ten days, and the duration - from 5 to 15 days (Merta \& Suderana, 2020; Miharja et al., 2020). Painful ulcers were treated topically with daily photobiomodulation therapy using a photobiomodulation therapy device (Twin Flex, M.M. Optics, Sao Carlos, Brazil). The authors did not take samples from oral lesions to check for the presence of the virus. However, oral lesions developed and disappeared at the same time as COVID-19, leading to speculation that oral lesions were indeed associated with COVID-19. However, it is still unknown whether these manifestations are directly caused by a virus or caused by immunosuppression associated with COVID-19 (Peng et al., 2020). Kamel A., Basuoni A., Salem Z. et al. Found a direct correlation between oral hygiene and the severity of COVID-19 by examining C-reactive protein values. The results obtained indicated that poor oral health was associated with increased blood C-reactive protein levels and a delayed recovery period. 


\section{Conclusions}

The study of materials related to this disease led to such conclusions as: there is insufficient clinical and diagnostic information about what is the root cause of the development of complications in the oral cavity during coronavirus infection - whether the virus itself or those drugs that patients received during pharmacotherapy, or they could be caused by other systemic diseases of the body. In COVID 19 (SARS-CoV-2), changes in OOM are not the primary cause, but are manifested as a result of drug treatment and disease progression, despite the fact that the oral cavity is one of the sources of entry gate for infection (Esselman, 2007; Langhorne et al., 2011).

\section{References}

Amorim dos Santos, J., Normando, A. G. C., Carvalho da Silva, R. L., Acevedo, A. C., De Luca Canto, G., Sugaya, N., ... \& Guerra, E. N. S. (2021). Oral manifestations in patients with COVID-19: a living systematic review. Journal of dental research, 100(2), 141-154.

Brandini, D. A., Takamiya, A. S., Thakkar, P., Schaller, S., Rahat, R., \& Naqvi, A. R. (2021). Covid-19 and oral diseases: Crosstalk, synergy or association?. Reviews in Medical Virology.

Chamorro-Petronacci, C., Martin Carreras-Presas, C., Sanz-Marchena, A., A Rodríguez-Fernández, M., María Suárez-Quintanilla, J., Rivas-Mundiña, B., ... \& Pérez-Sayáns, M. (2020). Assessment of the economic and health-care impact of COVID-19 (SARS-CoV-2) on public and private dental surgeries in Spain: A pilot study. International Journal of Environmental Research and Public Health, 17(14), 5139.

Drummond, J. F., Giansanti, J. S., Sabes, W. R., \& Smith, C. R. (1978). Sialadenoma papilliferum of the oral cavity. Oral Surgery, Oral Medicine, Oral Pathology,45(1), 72-75. https://doi.org/10.1016/00304220(78)90225-6

Esselman, P. C. (2007). Burn rehabilitation: an overview. Archives of physical medicine and rehabilitation, 88(12), S3-S6. https://doi.org/10.1016/j.apmr.2007.09.020

Kim, S. W., \& Su, K. P. (2020). Using psychoneuroimmunity against COVID-19. Brain, behavior, and immunity, 87, 4-5. https://doi.org/10.1016/j.bbi.2020.03.025

Langford, B. J., So, M., Raybardhan, S., Leung, V., Westwood, D., MacFadden, D. R., ... \& Daneman, N. (2020). Bacterial co-infection and secondary infection in patients with COVID-19: a living rapid review and metaanalysis. Clinical Microbiology and Infection. https://doi.org/10.1016/j.cmi.2020.07.016

Langhorne, P., Bernhardt, J., \& Kwakkel, G. (2011). Stroke rehabilitation. The Lancet, 377(9778), 1693-1702. https://doi.org/10.1016/S0140-6736(11)60325-5

Liang, K. (2020). Mathematical model of infection kinetics and its analysis for COVID-19, SARS and MERS. Infection, Genetics and Evolution, 82, 104306. https://doi.org/10.1016/j.meegid.2020.104306

Merta, I. N., \& Suderana, I. W. (2020). COVID-19 pandemic handling community social and cultural sector stimulus efforts. International Journal of Social Sciences and Humanities, 4(3), 1-12. https://doi.org/10.29332/ijssh.v4n3.434

Miharja, M. ., Setiawati, S. ., \& Lubis, A. L. P. . (2020). How dangerous the Indonesian recession due to COVID-19 pandemic: review policy and strategy to recovery. International Journal of Social Sciences and Humanities, 4(3), 121-129. https://doi.org/10.29332/ijssh.v4n3.470

Peng, X., Xu, X., Li, Y., Cheng, L., Zhou, X., \& Ren, B. (2020). Transmission routes of 2019-nCoV and controls in dental practice. International journal of oral science, 12(1), 1-6.

Qing, E., \& Gallagher, T. (2020). SARS coronavirus redux. Trends in immunology, 41(4), 271-273. https://doi.org/10.1016/j.it.2020.02.007

Saif, L. J. (1993). Coronavirus immunogens. Veterinary microbiology, 37(3-4), 285-297. https://doi.org/10.1016/0378-1135(93)90030-B

Sohrabi, C., Alsafi, Z., O'neill, N., Khan, M., Kerwan, A., Al-Jabir, A., ... \& Agha, R. (2020). World Health Organization declares global emergency: A review of the 2019 novel coronavirus (COVID-19). International journal of surgery, 76, 71-76.

Su, H. H., Chu, S. T., Hou, Y. Y., Chang, K. P., \& Chen, C. J. (2006). Spindle cell carcinoma of the oral cavity and oropharynx: factors affecting outcome. Journal of the Chinese Medical Association,69(10), 478-483. https://doi.org/10.1016/S1726-4901(09)70312-0

Tetro, J. A. (2020). Is COVID-19 receiving ADE from other coronaviruses?. Microbes and infection, 22(2), 72-73. https://doi.org/10.1016/j.micinf.2020.02.006

Xu, H., Zhong, L., Deng, J., Peng, J., Dan, H., Zeng, X., ... \& Chen, Q. (2020). High expression of ACE2 receptor of 2019-nCoV on the epithelial cells of oral mucosa. International journal of oral science, 12(1), 1-5. 